\title{
Assessment of Potential Factors that Effect Women Response to Labor Pain at Al-Elwyia Maternity Teaching Hospital
}

\author{
Sarab Nasr Fadhil ${ }^{1}$, Rabea Mohsen Ali ${ }^{1}$, Aqdas Dawood Salman ${ }^{1}$ \\ ${ }^{1}$ Maternal and Neonate Nursing Department, College of Nursing, University of Baghdad, Iraq
}

\begin{abstract}
This study aims to assess the potential factors that effect on women response to labor pain. A descriptive design was conducted on non-probability (Purposive Sample) of (60) pregnant women admitted to AlElwyia Maternity Teaching Hospital suffering from labor pain. The data were analyses used descriptive \& inferential statistical. The study results show a highly significant differences concerning factors aggravate labor pain regarding positive and negatives items generally, and there source factors have highly assessed completely as very enough which accounted (94\%), and service provider factors also extremely assessed good. The study concluded that there are many factors effect on women's coping with labor pain. The study recommended developing educational program for pregnant women teach them about all changes during period of pregnancy and labor, and initiation of childbirth classes in primary health care centers
\end{abstract}

Keywords: Assessment, factors, labor Pain.

\section{Introduction}

Labor pain is a part of a normal process in spite of the fact that it predictable during labor process, it is considered as the most unwanted part of the labor trial during childbirth. ${ }^{(1)}$ There are many factors that influence labor pain, include socio-demographic factors (such as age, education), physiological factors, parity, rupture of membranes, fetal factors, maternal position, psychological factors, non-preparation toward labor, expectations of labor, nursing support, family support, and cultural factors. ${ }^{(2)}$

\section{Methodology}

Descriptive designs was conducted on nonprobability (purposive sample) of (60) pregnant women that admitted to Al-Elwyia Maternity Teaching Hospital suffering from labor pain for the period of ( $4^{\text {th }}$ July 2018 through $24^{\text {th }}$ October 2018). Data were collected through used a questionnaire format, which consist of four parts.

\section{Corresponding Author:}

\section{Sarab Nasr Fadhil}

Instructor, Dr. Nursing College, University of Baghdad, Iraq

e-mail: sarab@conursing.uobaghdad.edu.iq
The pilot study was executed between the 25th June 2018 , to 1st July 2018 on (10) women to determine the reliability, and content validity was achieved through the 12 experts. Descriptive and inferential statistical analyses were used to analyze the data.

\section{Results}

Table (1): Distribution of the socio-demographic data

\begin{tabular}{|l|l|c|c|}
\hline \multirow{2}{*}{ Variables } & \multirow{2}{*}{ Groups } & \multicolumn{2}{|c|}{$(\mathbf{n}=\mathbf{6 0})$} \\
\cline { 2 - 4 } & & $\mathbf{N o .}$ & $\mathbf{~ \%}$ \\
\hline \multirow{4}{*}{$\begin{array}{l}\text { Age Groups (Per } \\
\text { Years) }\end{array}$} & $<20$ & 30 & $50 \%$ \\
\cline { 2 - 4 } & $20-24$ & 21 & $35 \%$ \\
\cline { 2 - 4 } & $25-29$ & 6 & $10 \%$ \\
\cline { 2 - 4 } & $30-34$ & 3 & $5 \%$ \\
\hline \multirow{4}{*}{$\begin{array}{l}\text { Educational level } \\
\text { of wife }\end{array}$} & Illiterate & 2 & $3.3 \%$ \\
\cline { 2 - 4 } & Read \& write & 5 & $8.3 \%$ \\
\cline { 2 - 4 } & Primary school & 20 & $33.3 \%$ \\
\cline { 2 - 4 } & Intermittent school & 16 & $26.7 \%$ \\
\cline { 2 - 4 } & Preparatory school & 7 & $11.7 \%$ \\
\cline { 2 - 4 } & Bachelor & 9 & $15 \%$ \\
\cline { 2 - 4 } & Higher studies & 1 & $1.7 \%$ \\
\hline \multirow{3}{*}{$\begin{array}{l}\text { Occupation status } \\
\text { of wife }\end{array}$} & Housewife & 56 & $93.3 \%$ \\
\cline { 2 - 4 } & Employee & 1 & $1.7 \%$ \\
\cline { 2 - 4 } & Free job & 3 & $5 \%$ \\
\hline
\end{tabular}

$* \%=$ Percentage 
Table (1) shows that the highest percentages $(50 \%)$ which are $(<20)$ years old. $(33.3 \%)$ which are primary, schools' graduates, $(93.3 \%)$ were housewives.

Table (2): Summary Statistics for Factors that Aggravate Labor Pain

\begin{tabular}{|c|c|c|c|c|c|}
\hline \multicolumn{2}{|l|}{ Factors } & \multirow{2}{*}{$\begin{array}{c}\text { MS } \\
1.6500\end{array}$} & \multirow{2}{*}{$\begin{array}{c}\text { SD } \\
.48099\end{array}$} & \multirow{2}{*}{$\begin{array}{c}\text { P-value } \\
0.040\end{array}$} & \multirow{2}{*}{$\begin{array}{l}\text { Ass } \\
\mathrm{NS}\end{array}$} \\
\hline \multirow{4}{*}{$\begin{array}{l}\text { Psychological } \\
\text { Factors }\end{array}$} & Anxiety & & & & \\
\hline & Fear of Birth Process & 1.8333 & .37582 & 0.000 & HS \\
\hline & Sense of loss of Control & 1.4500 & .50169 & 0.640 & NS \\
\hline & Stress & 1.4000 & .49403 & 0.210 & NS \\
\hline \multirow{5}{*}{$\begin{array}{l}\text { Physiological } \\
\text { Factors }\end{array}$} & Cervical dilation & 1.9833 & .12910 & 0.000 & HS \\
\hline & Decent of presenting part & 2.0000 & .00000 & .00000 & HS \\
\hline & $\begin{array}{l}\text { Frequency, Intensity, duration of Uterine } \\
\text { Contraction }\end{array}$ & 1.9667 & .18102 & 0.000 & HS \\
\hline & Position, presentation of Fetus & 2.0000 & .00000 & .00000 & HS \\
\hline & $\begin{array}{l}\text { Stretching the perineum area, pressure } \\
\text { on the Bladder }\end{array}$ & 2.0000 & .00000 & .00000 & HS \\
\hline \multirow{9}{*}{$\begin{array}{l}\text { Cultural and } \\
\text { religious beliefs }\end{array}$} & Family Support & 1.9000 & .30253 & 0.000 & HS \\
\hline & Family Problems & 1.1167 & .32373 & 0.000 & HS \\
\hline & Lack of Medical Support & 1.2833 & .45442 & 0.000 & HS \\
\hline & Mental Preparation & 1.7667 & .42652 & 0.000 & HS \\
\hline & Non-Preparation toward Labor & 1.5667 & .49972 & 0.470 & NS \\
\hline & Use Medication to Augmented Labor & 1.9333 & .25155 & 0.000 & HS \\
\hline & Cry & 1.7500 & .43667 & 0.000 & HS \\
\hline & Pray or call God & 1.7333 & .44595 & 0.000 & HS \\
\hline & Scream & 1.8667 & 1.28177 & 0.000 & HS \\
\hline \multirow{6}{*}{ Other Factors } & Urination & 1.3667 & .48596 & 0.080 & NS \\
\hline & Eating & 1.0167 & .12910 & 0.000 & HS \\
\hline & $\begin{array}{l}\text { Change Position (Sitting, Standing, } \\
\text { rolling in bed, Lying Down, Walking) }\end{array}$ & 1.7500 & .43667 & 0.000 & HS \\
\hline & Lack of sleep/Tiredness & 1.9333 & .25155 & 0.000 & HS \\
\hline & Massage & 1.3000 & .46212 & 0.000 & HS \\
\hline & Heat Pack/Pad & 1.0833 & .27872 & 0.000 & $\mathrm{HS}$ \\
\hline \multirow{4}{*}{ Environment Factors } & Bright Lights & 1.0667 & .25155 & 0.000 & HS \\
\hline & Noise & 1.2000 & .40338 & 0.000 & HS \\
\hline & Temperature (Cold) & 1.2167 & .41545 & 0.000 & HS \\
\hline & Temperature (Hot) & 1.0333 & .18102 & 0.000 & HS \\
\hline
\end{tabular}

${ }^{(*)}$ HS : Highly Sig. at $\mathrm{P}<0.01$; S: Sig. at $\mathrm{P}<0.05$; NS: Non Sig. at $\mathrm{P}>0.05$, MS: Mean Score, SD: standard deviation, Asse. Assessment.

Table (2): The results show the factors that aggravate labor pain,assigned that the observed responses regarding positive and negatives items are high significant generally, while left over items named (anxiety,sense of loss of control, and stress) in psychological factors and item named (non-preparation toward labor) in cultural and religious beliefs and item named (urination)have no significant differences are obtained at $\mathrm{P}>0.05$. 


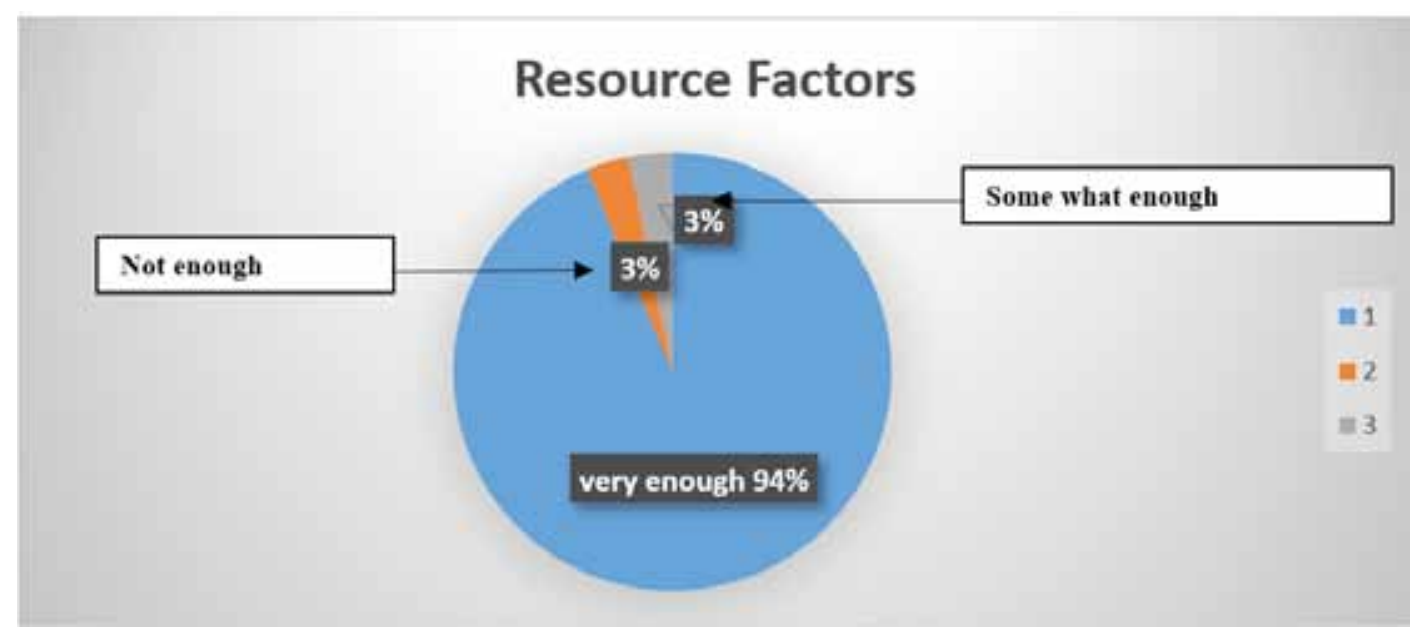

Figure (1): Summary Statistics for Resource Factors influencing laboring women perception on quality of intrapartum care

Figure (1) show that resource factors influencing laboring women perception on quality of intrapartum care's items concerning study group assigned that observed response has highly assessed completely as very enough which accounted (94\%) that named "The number of service providers, and availability of drugs, delivery beds, equipment and supplies", while, some women reported (3\%) for both somewhat enough, and not enough for the same items.

Table (3): Service provider factors influencing the laboring women perception on quality of intrapartum care

\begin{tabular}{|l|c|c|c|c|c|c|}
\hline \multirow{2}{*}{$\begin{array}{l}\text { Service provider factors influencing the laboring } \\
\text { women perception on quality of intrapartum care }\end{array}$} & \multicolumn{2}{|c|}{ Good } & \multicolumn{2}{|c|}{ Moderate } & \multicolumn{2}{c|}{ Poor } \\
\cline { 2 - 7 } & No. & Freq. & No. & Freq. & No. & Freq. \\
\hline Preparation for admission & 42 & $70 \%$ & 16 & $26.7 \%$ & 2 & $3.3 \%$ \\
\hline Efficiency of the admission procedure & 44 & $73.3 \%$ & 10 & $16.7 \%$ & 6 & $10.0 \%$ \\
\hline Attention of admitting & 43 & $71.7 \%$ & 12 & $20.0 \%$ & 5 & $8.3 \%$ \\
\hline Staff to individual needs & 37 & $61.7 \%$ & 19 & $31.6 \%$ & 4 & $6.7 \%$ \\
\hline Provision of information by nurses & 33 & $55.0 \%$ & 22 & $36.7 \%$ & 5 & $8.3 \%$ \\
\hline Concern and caring by the nurses & 32 & $53.3 \%$ & 22 & $36.7 \%$ & 6 & $10.0 \%$ \\
\hline How well the nurses listened & 29 & $48.3 \%$ & 24 & $40.0 \%$ & 7 & $11.7 \%$ \\
\hline Nurses attention to mothers' condition & 32 & $53.3 \%$ & 22 & $36.7 \%$ & 6 & $10.0 \%$ \\
\hline Availability of nurses when needed & 31 & $51.7 \%$ & 24 & $40.0 \%$ & 5 & $8.3 \%$ \\
\hline Nurses response to mothers, calls & 31 & $51.7 \%$ & 24 & $40.0 \%$ & 5 & $8.3 \%$ \\
\hline Skills and competence of the nurses & 44 & $73.3 \%$ & 14 & $23.3 \%$ & 2 & $3.3 \%$ \\
\hline
\end{tabular}

Freq. $=$ Frequency

Table (3): The results show that all quality of intrapartum care observed responses has highly and extremely assessed good.

\section{Discussion}

Regarding socio-demographic data: Table (1): Several demographic characteristics of women may have effect on women's perception to labor pain. Therefore, 
the demographic characteristics and their relations to labor pain have been studied, as the current study has reported a highest percentage (50\%) were at age group $(<20)$ years old ${ }^{(3)}$. This finding is in consistent with study which indicated that labor pain was found to be more severe in younger age as compared to those above 20 . The highest percentages (33.3\%)are primary schools graduates. These finding is in consistent with study show that women with low educational level will have minimum level of performance to cope with pain during childbirth process ${ }^{(4)}$. The height percentage of occupational status is "Housewives", and they are accounted (93.3\%). This finding is in constant with the study that found that majority of women (sixty percent in study group, and sixty four percent in control group) were not working. They explain that the occupation factor is one factor that can influence women to experience labor pain.

Factors that Aggravate Labor Pain: Table (2): This study is in agreement with a descriptive study made at Iraq governorate, (2007) for (100) pregnant women at three hospitals in Baghdad city which "The main results of the study reported a high mean of scores in women's fear on herself concerning labor (such as dystocia, demise during labor, uncontrolled uterine contractions, protracted labor, fear of being left alone, an episiotomy, and exposure to infection) and fear on their newborn from delivery of unhealthy or abnormal newborn delivery, shoulder dystocia, asphyxia, and exposure to cold and infection), so that a current study recommended program to teach the pregnant women aboutpsychological \& physiological changes during the pregnancy period and childbirth process $^{(6)}$. In addition to that, this study is in agreement with Australian and Swedish study that results suggest that psychological factors are significant factors concerning to birth consequence, due to have a passive effect on women's emotional health through pregnancy and increased the negative birth experience, so that must be clarify by health providers during the antenatal period to assist women in childbirth preparation ${ }^{(7)}$. Also, this study is agreement with study made in, (2004) which indicates that $(7 \%)$ of the sample had a passive birth experience that concern to many factors such as (Induction, Augmentation of labor, transfer of infant to neonatal care, unwanted pregnancy, loss of control, and take of obstetric analgesia. ${ }^{(8)}$ Furthermore, studies in Hong Kong, (2017) and study in Jordan (2005) present that labor pain is apprehension to have both psychological \& physiological origin, that contractions of uterus and dilation of cervix which are consider a physiological source ${ }^{(9 \& 10)}$ On top of that the women's perception toward labor pain can be effect by religious and cultural beliefs, In some culture, the women are shout and cry uncontrollable, while in other cultures they not explicit much distress the women's perception toward labor pain can be effect by religious and cultural beliefs, In some culture, the women are shout and cry uncontrollable, while in other cultures they not explicit much distress. Cultural factors can play important role in cope of women with pain during labor ${ }^{(11)}$. Finally, a significant positive relationship was found between labor stress \& pain and from environmental factors in primiparas and in multipara's women in study made in 2009. ${ }^{(12)}$

Resource Factors influencing laboring women perception on quality of intrapartum care: Figure (1) show that resource factors named "the number of service providers, and availability of drugs, delivery beds, equipment and supplies" have highly assessed completely as very enough which accounted (94\%) which mean that women agreed that these resources are available in maternity wards, and not effect on their perception of labor pain while just (3\%) of sample said unavailability of supplies and equipment. This result is agreement with result of study that has shown that some women experiences good health services during pregnancy, labor, and postpartum period. However, the lack of space, medical supplies, goods, human resources, and the passive behavior of health care providers is what most women face challenges while using services ${ }^{(13)}$.

Service provider factors influencing the laboring women perception on quality of intrapartum care: Table (3): The results show that all quality of intrapartum care observed responses has highly and extremely assessed good, this mean that the women copy positively with labor pain. This results agreement with study revealed that midwives' attitude and practice arise affirmative effect on women during labor, which gave a positive impression on the pregnant women's perception. Also, supportive relationship and high-quality care will empower the women in labor, thus assist the women to copy with her labor pain. ${ }^{(14)}$

Recommendation: The study recommended developing educational program for pregnant women teach them about all changes during period of pregnancy and labor, and initiation of childbirth classes in primary health care centers. 


\section{Conflict of Interest: Nil}

\section{Source of Funding: Self}

Ethical Clearance: Is obtained from the (ALElwyia maternity Teaching Hospital), and all pregnant women participants in the research - have been approved before the questionnaire is started.

\section{References}

1. Trout, KK.; The neuromatrix theory of pain: implications for selected non-pharmacologic method of pain relief for labor. Journal of Midwifery \& Women's Health, 2004, 49: 482-488,

2. Phumdoung, S., \& Rattanaparikonn, A.; Factors related to labor pain: review articles. Journal of Health Science and Medical Research, (2003), 21(2), 155-162.

3. Shrestha, I., Pradhan, N., \& Sharma, J. Factors influencing perception of labor pain among parturient women at Tribhuvan University teaching hospital. Nepal Journal of Obstetrics and Gynaecology, (2013). 8(1), 26-30.

4. Al Ahmar, E., \& Tarraf, S. Assessment of the sociodemographic factors associated with the satisfaction related to the childbirth experience. Open Journal of Obstetrics and Gynecology, (2014). 4(10), 585.

5. Nichols, F. and Zwelling, E.: Maternal-Newborn Nursing, Theory and Practice, philadelphis W.B. Saunders - company, 1997, PP. 729-30.

6. Rabea, M. Ali; Assessment of the fear of Delivery among Women at Labor; Sci. J. Nursing, (2007), $20,1-2$.

7. Haines, H. M., Rubertsson, C., Pallant, J. F., \& Hildingsson, I.; The influence of women's fear, attitudes, and beliefs of childbirth on mode and experience of birth. BMC Pregnancy and childbirth, (2012),12(1), 55.

8. Ulla Waldenström, Ingegerd Hildingsson, Christine Rubertsson RN, RM, MA, Ingela Rådestad; A Negative Birth Experience: Prevalence and Risk Factors in a National Sample; 19 March 2004,

9. Lee Lai Yin I. The experience of pain in the context of childbirth for Hong Kong Chinese women: a longitudinal cohort interview study. University of Central Lancashire; 2017.

10. Abushaikha L, Oweis A. Labour pain experience and intensity: A Jordanianperspective. Int J Nurs Pract. 2005;11(1):33-8.

11. Wee MYK, Tuckey JP, Thomas P, Burnard S. The IDVIP trial: a two centre randomized double blind controlled trial comparing intramuscular diamorphine and intramuscular pethidine for labor analgesia. BMC Pregnancy and Childbirth. 2011. 1151.

12. Pirdel M, Pirdel L. Perceived Environmental Stressors and Pain Perception During Labor among Primiparous and Multiparous Women. J Reprod Infertil. 2009;10(3):217-23.

13. Sigalla, G. N., Bakar, R. R., \& Manongi, R. N.; Experiences of facility-based delivery services among women of reproductive age in Unguja Island, Zanzibar: A Qualitative Study. J Fam Med, (2018). 5(4), 1149.

14. Oluyemisi, A. F., Oyadiran, G. O., Ijedimma, M. O., Akinlabi, B. O., \& Adewale, A. J. Perception of pregnant women towards midwives: attitude and practice during child delivery in health institutions in Ogbomoso, South-West, Nigeria. Epidemiology, Biostatistics and Public Health, (2014),11(2 